\title{
Annual growth and maturity function of the squat lobster Pleuroncodes monodon in central Chile
}

\author{
Rubén Roa \\ Instituto de Fomento Pesquero, Sede Zonal V-IX Regiones, Casilla 347, Talcahuano, Chile
}

\begin{abstract}
Length-frequency data (LFD) for the squat lobster Pleuroncodes monodon (Decapoda, Galatheidae) from 5 research surveys carried out in central Chile $\left(35^{\circ} 20^{\prime} \mathrm{S}\right.$ to $36^{\circ} 20^{\prime} \mathrm{S}$ ) between 1982 and 1991 were analysed to model male and female growth. The 1991 data were further used to model female maturity. From the 5 yr of LFD, 17 year classes were identified in males and 19 in females. To classify those year classes into age classes, a simple statistical procedure based on a stochastic dependency of growth on age was developed. The procedure classified male and female year classes into 6 and 7 age classes, respectively. Size variances due to within-year-class (individual) variability and among-year-classes (temporal) variability were estimated. The ratio between temporal and individual size variance did not increase with age. This indicates that size variation of individuals reaching a given age is mainly determined by the inherent variability of their year class rather than by environmental changes encountered across ages. A von Bertalanffy growth function provided a good description of both male and female growth. There were significant differences in the parameterization of the growth function between males and females: females were smaller than males for every age class. Logistic regression on female maturity data from 1991 shows that female squat lobsters reach maturity, as a population average, at intermediate sizes (ages). The $5 \%$ plausibility regions and $95 \%$ confidence intervals, as measures of uncertainty in maturity estimation, showed very similar interval estimates. The shape of the maturity curve corresponded to a stable population in terms of age structure.
\end{abstract}

\section{INTRODUCTION}

Growth estimation is a difficult task in crustaceans due to the loss of age marks during molting. One alternative is the use of length-frequency data (LFD). LFD analysis has been used to identify year classes, and then to fit growth functions, such as the von Bertalanffy equation, to the mean size of the year classes. Several graphical methods (Harding 1949, Cassie 1954, Bhattacharya 1967) have been and still are (Henmi 1992) used to accomplish this task. However, they lack statistical rigour because too much subjectivity is involved in the identification of year classes (Macdonald \& Pitcher 1979, Grant 1989), a problem that worsens as sample size decreases. Recent important advances are those of Macdonald \& Pitcher (1979) and Fournier et al. (1990, 1991). Macdonald \& Pitcher developed the MIX algorithm, a likelihoodprinciple based procedure to decompose a single collection of LFD into year classes, and under certain conditions, to estimate growth parameters using the von
Bertalanffy growth function. Fournier et al. (1990, 1991) developed the more sophisticated MULTIFAN algorithm, also a likelihood-principle based procedure to decompose a time series of LFD into year classes, to estimate growth and other important parameters. Here I show a simple procedure, which works with Macdonald \& Pitcher's MIX results, to group year classes from a time series of LFD into age classes. In this way, within- and between-year class size-at-age variances and growth parameters were estimated.

The main population of the squat lobster Pleuroncodes monodon is now under exploitation after 3 yr of fishery closure due to overfishing in the previous $7 \mathrm{yr}$ period (Roa \& Bahamonde in press). Scientific information on demographic parameters is urgently needed for management purposes. Individual growth is a fundamental aspect of biomass production and yield. Also, size (age) at maturity may have a large impact on exploitable biomass (Welch \& Foucher 1988). Therefore, in this paper I provide estimates of annual growth and female maturity of the squat lobster 


\section{MATERIALS AND METHODS}

Data source. Data on length frequency and maturity (as measured by number of ovigerous and nonovigerous females at size) was obtained from 5 research surveys done on the RV 'Itzumi' (April 1982, number of sampled individuals, $\mathrm{N}=12220$; April 1983, $\mathrm{N}=$ 13546; March 1984, $N=9923 ;$ March 1986, $N=7322$ ) and RV 'Abate Molina' (October 1991, $N=10139$ ). The research surveys were aimed at quantifying biomass and population size structure of the main squat lobster population in central Chile, the Achira population $\left(35^{\circ} 20^{\prime} \mathrm{S}\right.$ to $\left.36^{\circ} 20^{\prime} \mathrm{S}\right)$. Four surveys were carried out during a 7 yr exploitation period (1982 to 1988), while the last survey was done on the last year of a 3 yr fishery closure period (1989 to 1991). All these surveys were made with similar materials and methods (see Roa \& Bahamonde in press). The characteristics of the area and the Achira population can be found elsewhere (Roa \& Bahamonde in press). Body size was measured from random samples of the catch to the nearest millimeter, measuring from the base of the eye socket dorsally, along a line parallel to the mid-line, to the posterior edge of the carapace, i.e. carapace length $(C)$.

The data covers 31766 male lobsters and $21384 \mathrm{fe}$ male lobsters. For growth analysis, the whole data set was used. For maturity function analysis, only data from the 1991 cruise was used because this cruise was the only one done at the end of the single egg-bearing period, just before larval hatching (Palma \& Arana 1990). Hence it was considered that the 1991 data set provided a better picture of the egg-bearing process of the whole population.

Growth analysis. For each year, male and female LFD data sets were analysed separately and then the final fitted functions for both sexes were statistically compared using the analysis of residual sum of squares (ARSS) modified for nonlinear least-squares regression as in Chen et al. (1992).

The first step was to run the program MIX version 2.3 (Macdonald \& Pitcher 1979, Macdonald \& Green 1988j on every LFD set. Throughout, I assumed normal error distribution in size as a stochastic function of age, and estimated the parameters of the distribution mixtures without constraints. When the number of year classes present in the LFD is not known it is necessary to guess a number. Inspecting the histogram provides a guess. I used the number of year classes suggested by visual inspection, say $r$, and $r+1$ and $r-1$. Out of these 3 runs, I selected one using 2 criteria: (1) goodness of fit measured by the Chi-square statistics, and (2) the fitted distribution mixture should not include a year class with an unreasonably high standard deviation and/or an unreasonably low $(<5 \%)$ proportional participa- tion. Only in one case did I violate this rule: in the 1986 LFD of males, the year class with the largest mean (see Fig. 1) was excluded from further analysis due to its large negative effect on the quality of the growth analysis. It was similar to a highly influential outlier in least-squares regression.

The application of the computer algorithm and the selection criteria on the 5 yr of LFD produced 17 year classes for males and 19 year classes for females (see Fig. 1, Table 1). In every year, the number of year classes was too low to permit the estimation of the von Bertalanffy growth function using MIX. Therefore, growth had to be represented by the whole set of year classes obtained from 5 different years. This set of year classes had to be grouped into age classes (see Fig. 2). To do this grouping required a distance measure between adjacent year classes, represented by normal curves from MIX. The distance measure allows identification of some borders between adjacent year classes as being borders between age classes (see Fig. 2). A general expression to measure distance between normal curves is

$$
\begin{aligned}
d_{i} & =\left(\mu_{1+1}+\delta \sigma_{i+1}\right)-\left(\mu_{1}+\delta \sigma_{1}\right), \\
& =\left(\mu_{1+1}-\mu_{i}\right)+\delta\left(\sigma_{l+1}-\sigma_{i}\right),
\end{aligned}
$$

where $\mu_{1}$ and $\sigma_{i}$ are the mean and standard deviation respectively, of normal curve $i$ (a year class in our case), when the whole set of normal curves is ordered into ascending mean; and $\delta$ is a coefficient varying from 0 to $+\infty$. Eq. (1) means that distance between adjacent year classes is measured between points of equal cumulative probablity under the normal curve. The parameter $\delta$ is a weight imposed on the difference between standard deviations. (In a graphical sense, $\delta$ weights for the different shapes of the normal curves.) For example, if all year classes had the same variance, then no matter the value of $\delta$, the distance $d$ would be measured between means only. Conversely, if the difference between year-class variances is large, then the effect of $\delta$ on the distance measure would be significant. The parameter $\delta$ then weights the amount of temporal variability in the indeterminacy of size as a stochastic function of age. Consequently, this weighting factor is a natural consequence of analysing time series of LFD to identify groups of year classes belonging to the same age class, when there is a variance term due to temporal variability.

After finding a suitable measure of distance, that is a suitable measure of $\delta$ (see below), an age class was defined using the following decision rule: (1) evaluate the distance $d_{i, i+1}$ (Eq. 1) between adjacent year classes when all year classes are ordered into ascending mean size, and (2) identify all those distances $d_{i, i+1}>d_{i-1, i}$ and $>d_{i+1, i+2}$ as the borders of age classes. Thus an age 
class was defined as the set containing year classes between adjacent major jumps in a plot of year class ranking against size at a given point of cumulative probability (see Fig. 2).

Using this procedure, the problem of grouping the year classes into age classes is reduced to finding a suitable value for $\delta$. To define a value for $\delta$ I assumed that individuals of the same sex born on the same year in a single population would produce only one normal curve. This assumption is supported by previous research (Palma \& Arana 1990) and by recent results which indicate that recruitment of the squat lobster occurs only on April of each year (V. A. Gallardo \& co-workers, Dept Oceanología, Universidad de Concepción, Chile, unpubl.) after a single annual hatching period near November (Palma \& Arana 1990). Hence a suitable value of $\delta$ must not group 2 or more year classes from the same year into the same age class. Consequently, in time series of LFD composed of $n$ yr, the maximum number of year classes that can be grouped into a single age class is $n$, and those $n$ must be from different years. As an increase in $\delta$ causes a decrease in the number of age classes, the above constraint provides an upper bound for $\delta$. A lower bound was obtained as follows: a decrease in $\delta$ causes an increase in the number of age classes, which in turn causes a change in the estimated asymptotic size and Brody growth coefficient, depending on where the new age class was placed by the new value of $\delta$. Thus, a lower bound for $\delta$ was obtained by excluding values below a threshold in which the estimated asymptotic size was too low or too high given the maximum observed sizes (Chen et al. 1992). Given these constraints, a value of $\delta$ was iteratively searched.

The grouping of year classes into age classes allows the identification of a variance due to within-year-class (individual) size variability and among-year-classes (temporal) size variability. For a given age class, individual variance can be calculated as the pooled and weighted variance of all the year classes composing it. On the other hand, temporal variance can be obtained from the deviation around the weighted mean size of the age class.

Visual inspection of the size progression of the age classes showed that the von Bertalanffy function provided a good model of the age-size relationship (see Fig. 2). Parameterization of the von Bertalanffy function,

$$
C(t)=C_{\mathrm{so}}\left\{1-\exp \left[-k\left(t-t_{0}\right)\right]\right\}
$$

where $C$ is carapace length, $t$ is age, $C_{\infty}$ is asymptotic carapace length, $k$ is the Brody growth coefficient, and $t_{0}$ is the age at zero size, was achieved from nonlinear least-squares estimation using module NONLIN of
SYSTAT version 4.0 (Wilkinson 1988). This estimation did not include the first year class of males and that of females, because they were poorly represented and most likely their mean sizes were overestimated by the selectivity of the fishing gear (see Fournier et al. 1990 for a discussion of this problem). The iteration algorithm was quasi-Newton.

For estimation, arbitrary ages were assigned to each age class. The integer part of the assigned age was obtained as that providing the nearest-to-zero negative $t_{0}$ estimation (Chen et al. 1992). The decimal part of the assigned ages was obtained by dividing the number of the month of the cruise, counted from the month of birth (November; Palma \& Arana 1990) by 12. It must be emphasized that the assignment of absolute ages to age classes did not affect the estimation of the growth parameters $k$ and $C_{\infty}$. The estimation of these parameters was completely determined by the grouping of year classes into age classes, that is, by the coefficient $\delta$ in Eq. (1), and mean sizes computed from MIX.

Maturity function estimation. The 1991 LFD provided estimates of the egg-bearing fractions at size. By plotting this egg-bearing fraction against size (Fig. 4), it became clear that a logistic function would appropriately describe the maturity process, as for other crustaceans (Campbell \& Robinson 1983, Fogarty \& Idoine 1988, Restrepo \& Watson 1991). Hence,

$$
P(C)=\frac{\beta}{1+\exp \left(\alpha_{1}+\alpha_{2} C\right)}
$$

where $P(C)$ is the fraction of females bearing eggs as a function of size, $C$ is size (carapace length), and $\beta, \alpha_{1}$, and $\alpha_{2}$ are the asymptote, position, and slope parameters respectively. Previous inspection of Fig. 4 showed that the logistic curve approached 1 as size increased. Thus the parameter $\beta$ was fixed at 1 .

Other sigmoid functional forms are possible (Welch \& Foucher 1988, Schnute \& Richards 1990), however this one was chosen for its simplicity in deriving estimators such as the average size at which maturation occurs. Given the binomial nature of maturity data and the nonlinear relationship between egg-bearing fractions and size, I estimated the parameters in Eq. (3) via maximum likelihood estimation (m.l.e.), where

$$
L\left(\beta, \alpha_{1}, \alpha_{2}\right)=\sum[(h) \ln \{P(C)\}+(1-h) \ln \{1-P(C)\}]
$$

is the log likelihood function to be maximized, where $h$ is a dichotomous variable representing presence $(h=1)$ or absence ( $h=0$ ) of eggs, $P(C)$ is Eq. (3), and the sum is over all observations (Shanubhogue \& Gore 1987, Wilkinson 1988, Hosmer \& Lemeshow 1989). In Eq. (4) a constant term has been omitted because it does not affect parameter estimation. By taking partial derivatives of $L$ with respect to the parameters $\alpha_{1}$ 

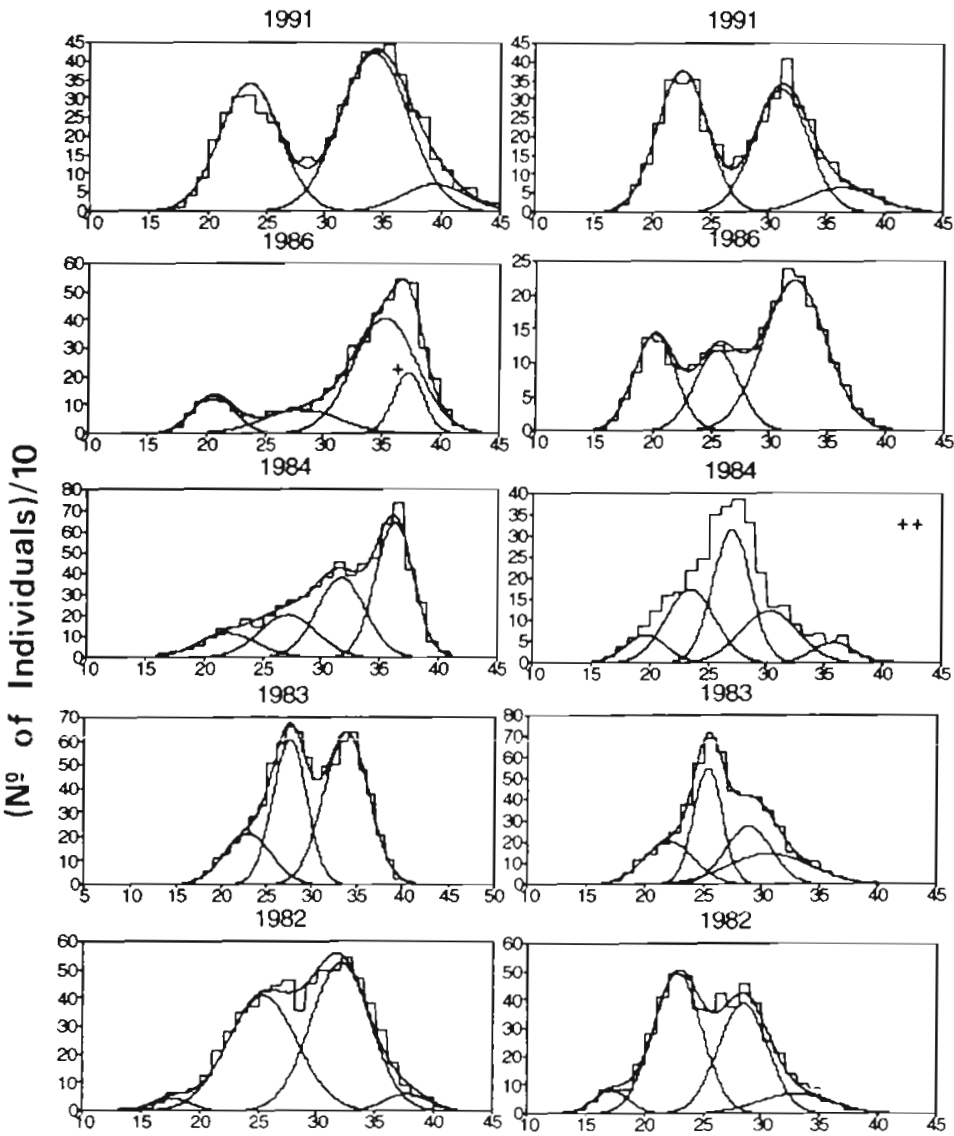

Carapace Length $(\mathrm{mm})$

Fig. 1. Pleuroncodes monodon. Year class composition of lengthfrequency data from MIX analysis. Left column: males; right column: females. Histograms: raw data; lines: estimated normal components and fitted distribution mixture. +: year class not included in growth analysis. ++ : fitted distribution mixture not included due to software limitations

and $\alpha_{2}$, equating to zero, and iteratively solving for $\alpha_{1}$ and $\alpha_{2}$, m.l.e. of these parameters is obtained. Computation of m.l.e. for the parameters of the logistic function was achieved using module NONLIN of SYSTAT version 4.0 (Wilkinson 1988). Uncertainty in parameter estimation was evaluated using 2 different procedures: $95 \%$ confidence interval from SYSTAT robust computation of asymptotic standard errors and $5 \%$ plausibility regions (Welch \& Foucher 1988). This latter uncertainty measure was obtained by fixing the value of one parameter at several levels and estimating the other until the negative of the log likelihood function increased in 3 units with respect to the minimum value (Welch \& Foucher 1988). The iterative algorithm for m.l.e. was quasi-Newton. The sample size was 4413 females ranging from 17 to $45 \mathrm{~mm} \mathrm{C}$. A point of particular biological relevance is the size at $50 \%$ sexual maturity, $C_{50 \%}$ (Welch \& Foucher 1988), since it is the average size at which maturation occurs. By solving Eq. (4) at $P=0.5$, $C_{50 \%}=-\alpha_{1} / \alpha_{2}$

\section{RESULTS}

\section{Growth}

Fig. 1 and Table 1 show the results from MIX analysis. Under the assumption of a normal random determination of size as a stochastic function of age, 17 year classes were identified for males and 19 for females throughout the $5 \mathrm{yr}$ of data. It is important to note in Table 2 the very small standard errors corresponding to the estimation of the mean, standard deviation, and proportion of participåtion in the distuibution mixtures.

To identify groups of year classes belonging to the same age class, the distance between points of equal cumulative probability was computed using Eq. (1). For males, values of $\delta$ equal to 0.43 or less, and equal to 1.29 or more yielded unreliable or unacceptable results, in terms of $C_{\infty}$ and the fundamental assumption that a single year class should not produce 2 or more normal curves. When $\delta$ was set at $0.667 \quad(75 \%$ cumulative probability) Eq. (2) classified the 17 year classes into 6 age classes, with a maximum number of 5 year classes in some age classes (Fig. 2a), all belonging to different years. This grouping yielded reliable estimates of $C_{\infty}$. Using the same criteria, the acceptable value of $\delta$ for females was also 0.667 , classifying the 19 year classes into 7 age classes (Fig. 2b).

Growth seemed to approximate a von Bertalanffy function. For males, the iterations converged in estimating the 3 parameters (Table 2). For females, however, the iterations did not converge to a feasible parameter space when estimating the 3 parameters. To run the iterations with only 2 parameters, I used the value of $\mathrm{t}_{0}$ obtained from males. This procedure yielded only a small difference of initial size between the sexes ( $1 \mathrm{~mm}$ ), but did not affect the estimation of $k$ and $C_{\infty}$ at all (Table 2).

The residuals of the fitted function against the assigned ages for females did not behave in a completely random way (Fig. 3b): residuals are positive for early and late ages, and negative for intermediate ages. For both however, males and females, the variance explained by the von Bertalanffy model, as a measure of goodness of fit (Chen et al. 1992), was very high (Table 2). 
Table 1. Pleuroncodes monodon. Results from MIX analysis. Year classes are ordered into ascending mean size. SD: standard deviation; P: proportion of participation in the distribution mixture. Standard error in parentheses

\begin{tabular}{|c|c|c|c|c|c|c|c|c|}
\hline \multirow{2}{*}{$\begin{array}{l}\text { Year } \\
\text { class }\end{array}$} & \multicolumn{4}{|c|}{ Males } & \multicolumn{4}{|c|}{ Females } \\
\hline & $\begin{array}{l}\text { Survey date } \\
\text { (month/year) }\end{array}$ & $\begin{array}{l}\text { Mean } \\
(\mathrm{mm})\end{array}$ & $\begin{array}{l}\mathrm{SD} \\
(\mathrm{mm})\end{array}$ & $\mathrm{P}$ & $\begin{array}{l}\text { Survey date } \\
\text { (month/year) }\end{array}$ & $\begin{array}{l}\text { Mean } \\
(\mathrm{mm})\end{array}$ & $\begin{array}{c}\mathrm{SD} \\
(\mathrm{mm})\end{array}$ & $\mathrm{P}$ \\
\hline 1 & $4 / 82$ & $\begin{array}{l}17.11 \\
(0.24)\end{array}$ & $\begin{array}{l}1.78 \\
(0.17)\end{array}$ & $\begin{array}{c}0.025 \\
(0.003)\end{array}$ & $4 / 82$ & $\begin{array}{l}17.16 \\
(0.14)\end{array}$ & $\begin{array}{l}1.50 \\
(0.10)\end{array}$ & $\begin{array}{c}0.055 \\
(0.003)\end{array}$ \\
\hline 2 & $3 / 86$ & $\begin{array}{l}20.85 \\
(0.11)\end{array}$ & $\begin{array}{c}1.92 \\
(0.08)\end{array}$ & $\begin{array}{c}0.134 \\
(0.005)\end{array}$ & $3 / 84$ & $\begin{array}{l}19.68 \\
(0.26)\end{array}$ & $\begin{array}{c}1.75 \\
(0.18)\end{array}$ & $\begin{array}{c}0.082 \\
(0.007)\end{array}$ \\
\hline 3 & $3 / 84$ & $\begin{array}{l}22.05 \\
(0.17)\end{array}$ & $\begin{array}{c}2.47 \\
(0.13)\end{array}$ & $\begin{array}{c}0.109 \\
(0.005)\end{array}$ & $3 / 86$ & $\begin{array}{l}20.17 \\
(0.10)\end{array}$ & $\begin{array}{l}1.76 \\
(0.07)\end{array}$ & $\begin{array}{c}0.235 \\
(0.009)\end{array}$ \\
\hline 4 & $4 / 83$ & $\begin{array}{l}22.96 \\
(0.12)\end{array}$ & $\begin{array}{c}2.57 \\
(0.09)\end{array}$ & $\begin{array}{c}0.170 \\
(0.006)\end{array}$ & $4 / 83$ & $\begin{array}{l}22.09 \\
(0.11)\end{array}$ & $\begin{array}{c}2.14 \\
(0.08)\end{array}$ & $\begin{array}{c}0.201 \\
(0.007)\end{array}$ \\
\hline 5 & $10 / 91$ & $\begin{array}{l}23.59 \\
(0.07)\end{array}$ & $\begin{array}{c}2.56 \\
(0.05)\end{array}$ & $\begin{array}{c}0.380 \\
(0.007)\end{array}$ & $10 / 91$ & $\begin{array}{l}22.59 \\
(0.06)\end{array}$ & $\begin{array}{c}2.14 \\
(0.04)\end{array}$ & $\begin{array}{c}0.201 \\
(0.008)\end{array}$ \\
\hline 6 & $4 / 82$ & $\begin{array}{l}24.19 \\
(0.08)\end{array}$ & $\begin{array}{c}2.88 \\
(0.07)\end{array}$ & $\begin{array}{c}0.442 \\
(0.008)\end{array}$ & $4 / 82$ & $\begin{array}{l}22.83 \\
(0.06)\end{array}$ & $\begin{array}{c}2.06 \\
(0.05)\end{array}$ & $\begin{array}{c}0.472 \\
(0.008)\end{array}$ \\
\hline 7 & $3 / 84$ & $\begin{array}{l}27.18 \\
(0.15)\end{array}$ & $\begin{array}{c}2.39 \\
(0.17)\end{array}$ & $\begin{array}{c}0.189 \\
(0.005)\end{array}$ & $3 / 84$ & $\begin{array}{l}23.52 \\
(0.14)\end{array}$ & $\begin{array}{l}2.10 \\
(0.21)\end{array}$ & $\begin{array}{c}0.272 \\
(0.012)\end{array}$ \\
\hline 8 & $4 / 83$ & $\begin{array}{l}27.80 \\
(0.07)\end{array}$ & $\begin{array}{c}2.03 \\
(0.08)\end{array}$ & $\begin{array}{c}0.367 \\
(0.008)\end{array}$ & $4 / 83$ & $\begin{array}{l}25.41 \\
(0.06)\end{array}$ & $\begin{array}{l}1.23 \\
(0.05)\end{array}$ & $\begin{array}{c}0.310 \\
(0.010)\end{array}$ \\
\hline 9 & $3 / 86$ & $\begin{array}{l}27.93 \\
(0.23)\end{array}$ & $\begin{array}{c}2.37 \\
(0.17)\end{array}$ & $\begin{array}{c}0.105 \\
(0.006)\end{array}$ & $3 / 86$ & $\begin{array}{l}25.53 \\
(0.16)\end{array}$ & $\begin{array}{c}1.87 \\
(0.12)\end{array}$ & $\begin{array}{c}0.208 \\
(0.010)\end{array}$ \\
\hline 10 & $4 / 82$ & $\begin{array}{l}31.17 \\
(0.07)\end{array}$ & $\begin{array}{c}2.62 \\
(0.09)\end{array}$ & $\begin{array}{c}0.493 \\
(0.008)\end{array}$ & $3 / 84$ & $\begin{array}{l}27.05 \\
(0.10)\end{array}$ & $\begin{array}{l}1.60 \\
(0.11)\end{array}$ & $\begin{array}{c}0.370 \\
(0.013)\end{array}$ \\
\hline 11 & $3 / 84$ & $\begin{array}{l}31.72 \\
(0.10)\end{array}$ & $\begin{array}{c}2.07 \\
(0.10)\end{array}$ & $\begin{array}{c}0.303 \\
(0.008)\end{array}$ & $4 / 82$ & $\begin{array}{l}28.44 \\
(0.08)\end{array}$ & $\begin{array}{c}2.09 \\
(0.07)\end{array}$ & $\begin{array}{c}0.373 \\
(0.009)\end{array}$ \\
\hline 12 & $4 / 83$ & $\begin{array}{l}33.95 \\
(0.41)\end{array}$ & $\begin{array}{c}2.35 \\
(0.15)\end{array}$ & $\begin{array}{c}0.304 \\
(0.009)\end{array}$ & $4 / 83$ & $\begin{array}{l}28.90 \\
(0.19)\end{array}$ & $\begin{array}{c}1.98 \\
(0.11)\end{array}$ & $\begin{array}{c}0.250 \\
(0.015)\end{array}$ \\
\hline 13 & $10 / 91$ & $\begin{array}{l}34.26 \\
(0.07)\end{array}$ & $\begin{array}{c}2.91 \\
(0.08)\end{array}$ & $\begin{array}{c}0.537 \\
(0.008)\end{array}$ & $3 / 84$ & $\begin{array}{l}30.32 \\
(0.19)\end{array}$ & $\begin{array}{c}2.38 \\
(0.21)\end{array}$ & $\begin{array}{c}0.215 \\
(0.017)\end{array}$ \\
\hline 14 & $4 / 82$ & $\begin{array}{l}35.37 \\
(0.58)\end{array}$ & $\begin{array}{c}2.36 \\
(0.35)\end{array}$ & $\begin{array}{c}0.039 \\
(0.004)\end{array}$ & $4 / 83$ & $\begin{array}{l}30.66 \\
(0.28)\end{array}$ & $\begin{array}{c}3.50 \\
(0.20)\end{array}$ & $\begin{array}{c}0.239 \\
(0.011)\end{array}$ \\
\hline 15 & $3 / 86$ & $\begin{array}{l}35.64 \\
(0.05)\end{array}$ & $\begin{array}{c}2.62 \\
(0.04)\end{array}$ & $\begin{array}{c}0.761 \\
(0.007)\end{array}$ & $10 / 91$ & $\begin{array}{l}31.08 \\
(0.07)\end{array}$ & $\begin{array}{c}2.31 \\
(0.07)\end{array}$ & $\begin{array}{c}0.431 \\
(0.011)\end{array}$ \\
\hline 16 & $3 / 84$ & $\begin{array}{l}36.27 \\
(0.05)\end{array}$ & $\begin{array}{c}1.61 \\
(0.03)\end{array}$ & $\begin{array}{c}0.399 \\
(0.007)\end{array}$ & $3 / 86$ & $\begin{array}{l}32.17 \\
(0.09)\end{array}$ & $\begin{array}{c}2.67 \\
(0.07)\end{array}$ & $\begin{array}{c}0.557 \\
(0.011)\end{array}$ \\
\hline 17 & $10 / 91$ & $\begin{array}{l}39.44 \\
(0.31)\end{array}$ & $\begin{array}{c}2.70 \\
(0.21)\end{array}$ & $\begin{array}{c}0.083 \\
(0.005)\end{array}$ & $4 / 82$ & $\begin{array}{l}32.95 \\
(0.25)\end{array}$ & $\begin{array}{c}3.14 \\
(0.19)\end{array}$ & $\begin{array}{c}0.101 \\
(0.005)\end{array}$ \\
\hline 18 & & & & & $3 / 84$ & $\begin{array}{l}35.83 \\
(0.20)\end{array}$ & $\begin{array}{c}1.73 \\
(0.14)\end{array}$ & $\begin{array}{c}0.062 \\
(0.012)\end{array}$ \\
\hline 19 & & & & & $10 / 91$ & $\begin{array}{l}36.36 \\
(0.24)\end{array}$ & $\begin{array}{c}2.99 \\
(0.18)\end{array}$ & $\begin{array}{c}0.111 \\
(0.006)\end{array}$ \\
\hline
\end{tabular}

There is a clear difference between both sexes in terms of the parameterization of their growth function (Fig. 3a; Table 2). A statistical comparison (Chen et al. 1992) confirms this interpretation $(F(2,29)=67.711$, $p<0.005)$.

The ratio between temporal and individual size variances (Table 3) does not change with age both for males and females (Spearman's rank correlation coefficient, $\mathrm{p}>0.1$ ).

\section{Maturity function estimation}

M.le. of the logistic function parameters (Table 2) yielded a rather steep curve (Fig. 4a). The progression from immaturity to maturation shows a succesive increase in the proportion of mature lobsters with size, corresponding to a Type II distribution of Trippel \& Harvey (1991). The average size at which maturation occurs, $C_{50 \%}$ (Table 2) is intermediate (Fig. 4a). Most 
Table 2. Pleuroncodes monodon. Growth and maturity parameters of the squat lobster and related information. Standard errors in parentheses. Notation follows the text

\begin{tabular}{|lcc|}
\hline Growth & Males & Females \\
\hline$C_{\infty}(\mathrm{mm})$ & $50.45(9.11)$ & $44.55(3.11)$ \\
$k\left(\mathrm{yr}^{-1}\right)$ & $0.197(0.091)$ & $0.179(0.022)$ \\
$t_{0}(\mathrm{yr})$ & $-0.51(0.70)$ & -0.51 (fixed) \\
$\mathrm{r}^{2}$ & 0.969 & 0.937 \\
Maturity & Females \\
\hline$\beta$ & 1 (fixed) \\
$\alpha_{1}$ & $13.648(0.370)$ \\
$\alpha_{2}$ & $-0.502(0.013)$ \\
$L\left(\alpha_{1}, \alpha_{2}\right)$ & 1446.695 \\
$C_{50 \%}(95 \%$ interval $)$ & $27.2(24.2,30.2)$ \\
\hline
\end{tabular}
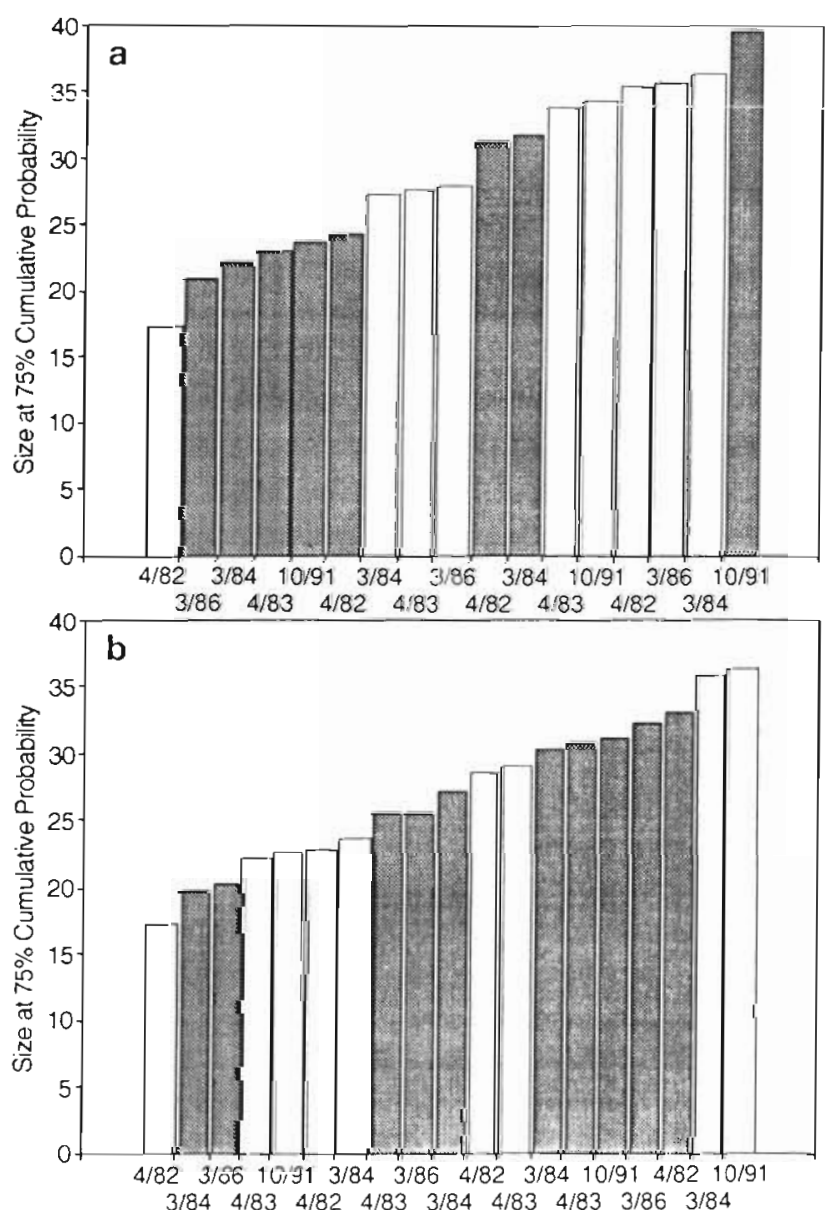

Fig. 2. Pleuroncodes monodon. Size at $75 \%$ cumulative probability of year classes identified by MIX for (a) male and (b) female squat lobster. On the abcissa the date of survey is shown (month/year). Adjacent age classes are shown by contrasting fill patterns
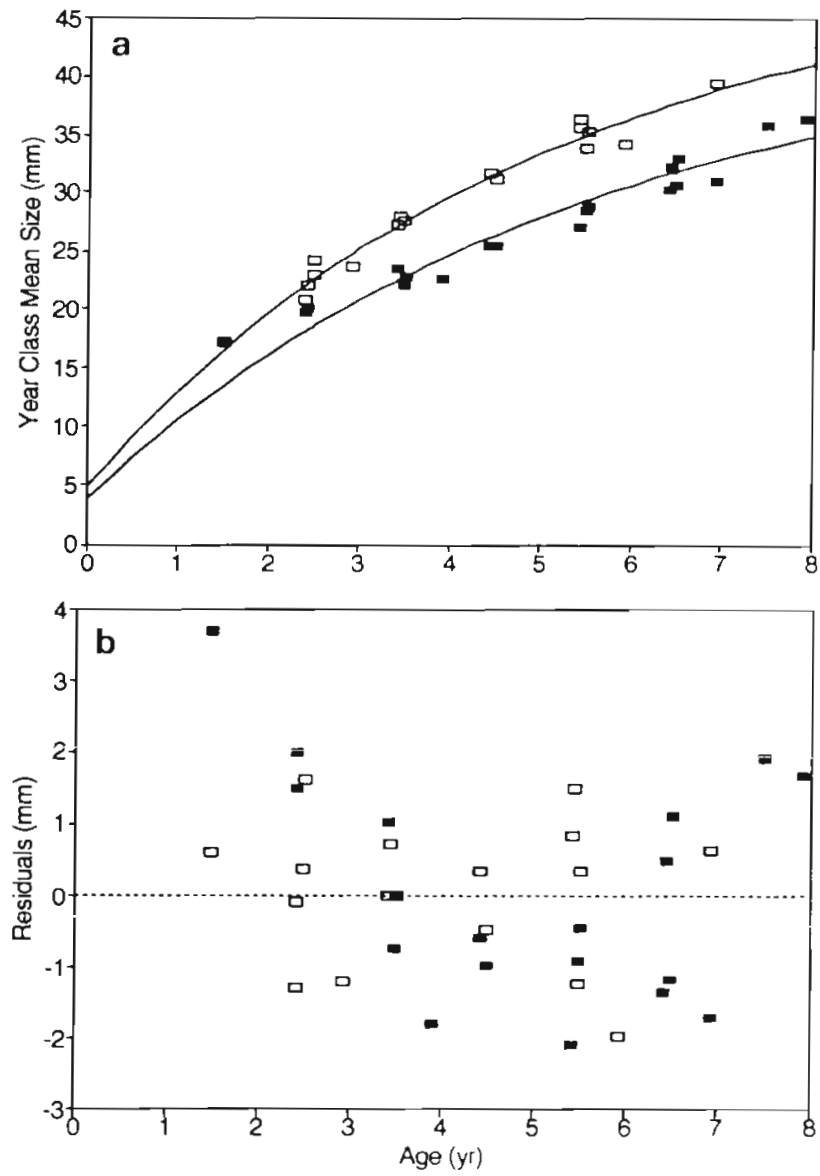

Fig. 3. Pleuroncodes monodon. Von Bertalanffy growth function of male and females squat lobster. (a) males; (-) females. (a) Fitted function (line) and calculated mean size of year classes (squares). (b) Residuals of growth model

Table 3. Pleuroncodes monodon. Relationship between individual and temporal variance of size at age. $C$ : weighted mean size at age $\sigma_{\gamma}$ : weighted temporal standard deviation; $\sigma_{y}$ : individual standard deviation; $R=\sigma_{\gamma} / \sigma_{y}$

\begin{tabular}{|c|c|c|c|c|c|}
\hline Sex & $\begin{array}{l}\text { Age } \\
\text { class }\end{array}$ & $\begin{array}{c}C \\
(m m)\end{array}$ & $\begin{array}{c}\sigma_{Y} \\
(\mathrm{~mm})\end{array}$ & $\begin{array}{c}\sigma_{y} \\
(\mathrm{~mm})\end{array}$ & $R$ \\
\hline \multirow[t]{6}{*}{ Males } & 1 & 17.11 & - & 1.78 & - \\
\hline & 2 & 22.73 & 1.32 & 2.61 & 0.50 \\
\hline & 3 & 27.64 & 0.40 & 2.07 & 0.19 \\
\hline & 4 & 31.45 & 0.39 & 2.43 & 0.16 \\
\hline & 5 & 35.10 & 0.97 & 2.47 & 0.39 \\
\hline & 6 & 39.44 & - & 2.70 & - \\
\hline \multirow[t]{7}{*}{ Females } & 1 & 17.16 & - & 1.50 & - \\
\hline & 2 & 19.93 & 0.35 & 1.76 & 0.20 \\
\hline & 3 & 22.76 & 0.60 & 2.10 & 0.28 \\
\hline & 4 & 26.00 & 0.91 & 1.48 & 0.62 \\
\hline & 5 & 28.67 & 0.33 & 2.05 & 0.16 \\
\hline & 6 & 31.06 & 0.80 & 2.78 & 0.29 \\
\hline & 7 & 36.10 & 0.38 & $2.6 ?$ & 0.14 \\
\hline
\end{tabular}



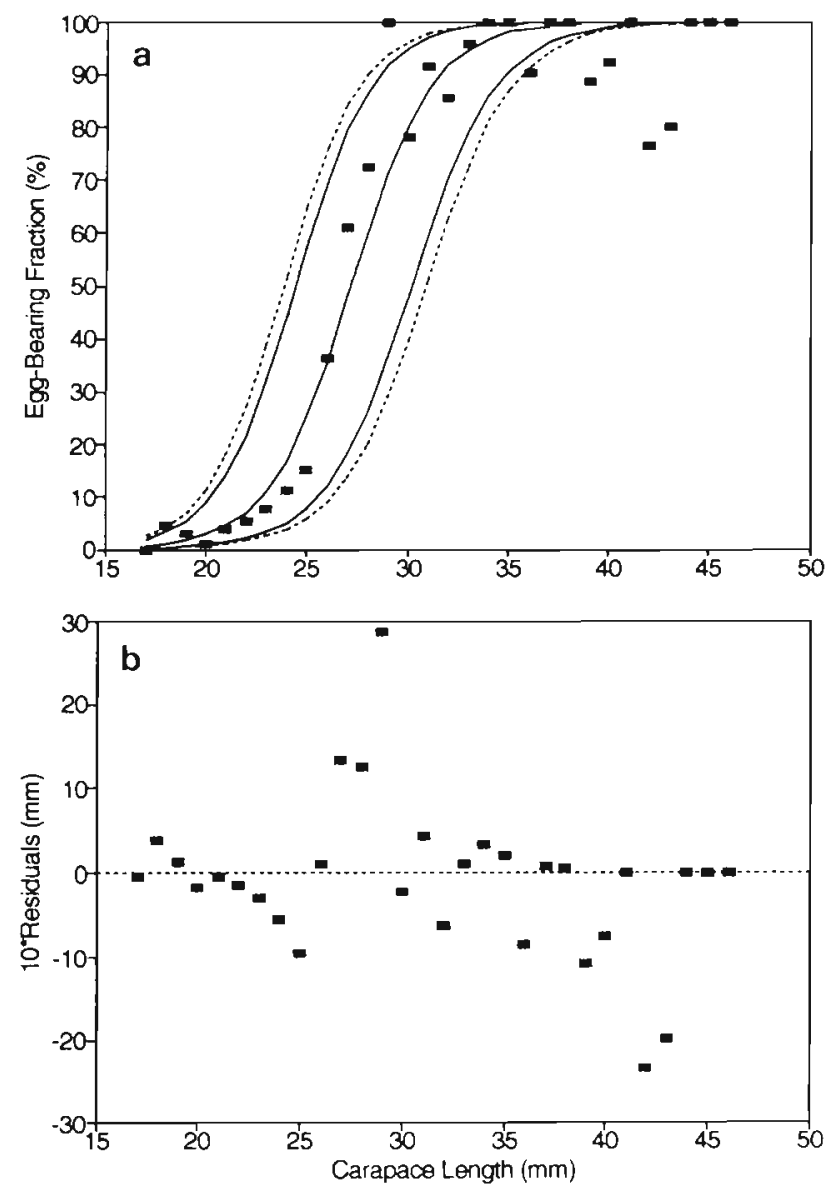

Fig. 4. Pleuroncodes monodon. Maturity function of female squat lobsters. (a) Fitted function (central solid line), $95 \%$ confidence intervals (exterior solid lines), 5\% plausibility limits (exterior dotted lines) and raw data (-). (b) Residuals of maturity model

females are mature at $30 \mathrm{~mm}$ carapace length (Fig. 4a). Residuals increased toward the intermediate range of sizes (Fig. 4b), a consequence of the binomial distribution of the errors. Some size intervals above $41 \mathrm{~mm}$ showed low values of the egg-bearing fraction. This can be attributed to small sample size at those sizes and possibly to large-sized females having started larval hatching by the time of sampling. A logistic regression done without values above $41 \mathrm{~mm}$ did not significantly alter the estimates, so those obtained with the whole data set were accepted.

The uncertainty associated with maturity estimation did not depend on the particular method used. The $95 \%$ confidence interval and $5 \%$ plausibility region (Welch \& Foucher 1988) were very similar (Fig, 4a). These 2 measures of uncertainty have different interpretations but they are asymptotically equivalent (Welch \& Foucher 1988). Our results with large sample size $(\mathrm{N}=4413)$ are an example of such asymptotical behaviour.

\section{DISCUSSION}

\section{Methodological aspects of growth analysis}

LFD from any year yielded too few year classes to fit a growth function with the MIX algorithm. However, the set of year classes from the 5 yr provided a wider spectrum of sizes at age. Therefore a procedure was developed to group the set of year classes into age classes. This grouping completely determined the estimation of asymptotic length and Brody growth coefficient in fitting a von Bertalanffy growth function. There are 2 sources of subjectivity in this procedure. First, the selection of the number of year classes for any year when using the MIX algorithm. This is a serious problem when sample sizes are small. In addition, it seems that an underestimation of the number of year classes is worse than an overestimation in estimating the Brody growth coefficient (Rosenberg \& Beddington 1987). In our case however, the average sample size was $4277 \mathrm{yr}^{-1}$ for females and $6353 \mathrm{yr}^{-1}$ for males, hence only very poorly represented and/or very high variance year classes could have escaped our attention.

A second source of subjectivity was the selection of the value for the parameter $\delta$ in calculating the distance between points of cumulative probability of adjacent year classes (ordered into ascending mean size; Eq. 1). This value determined the number of age classes into which the year classes were grouped by the decision rule and hence the estimation of $C_{\mathrm{s}}$ and $k$. It was already noted that increasing the value of $\delta$ reduces the number of age classes into which year classes are grouped. This fact provided, given some contraints and assumptions, objective upper and lower bounds $(0.43<\delta<1.29)$ for $\delta$. Thus this source of subjectivity in our procedures was at least objectively constrained.

A more sophisticated and general procedure for analysing time series of LFD is the MULTIFAN algorithm of Fournier et al. $(1990,1991)$. However, MULTIFAN does not completely remove the need to introduce subjective decisions in LFD analysis (Fournier et al. 1990). In this regard, the statement by Sparre (1987) and Sparre et al. (1989) that LFD analysis will probably never be entirely objective can only be supported. The procedure used here also requires subjective decisions, but introduces objective constraints to this subjectivity, as does MULTIFAN. The method worked well for the squat lobster, and may even be useful in other organisms. However I do not advocate its use in place of more sophisticated and general alternatives like MULTIFAN. MULTIFAN has several advantages like the estimation of important parameters other than growth: size selectivity of the first age class, parame- 
ters associated to a dependency of standard deviation on mean size, relative year class strengths, and even mortality in some cases (Fournier et al. 1990, 1991). Nevertheless, a potentially important advantage of the method used here for the analysis of time series of LFD is the ability to directly calculate within (individual) and among (temporal) year classes size variance.

\section{Biological aspects of growth analysis}

The ratio between temporal and individual size variance does not increase with age. That is, the size of individuals reaching a given age in different years is mainly determined by the inherent variability of their year class rather than by changes in the environment that they happen to face across ages.

Growth in crustaceans is composed of 2 factors: moulting frequency and size increment per molt. The most appropriate modeling approach should consider these factors (Saila et al. 1979, Campbell \& Robinson 1983, Fogarty \& Idoine 1988). However, the only reliable way to estimate empincai growth modeis is with tag-recapture data or direct experimental observations. No such data were available for the squat lobster, determining the need to use an approximate description. Many authors find it valuable to approximate crustacean growth with a von Bertalanffy growth function (Campbell 1983, Anderson 1991, Plaut \& Fishelson 1991, Somers \& Kirkwood 1991, Bergström 1992), even with tag-recapture data (Campbell 1983, Somers \& Kirkwood 1991) or experimental observations (Plaut \& Fishelson 1991), which may produce an empirical growth model. Thus, as a first approximation to squat lobster growth, a von Bertalanffy function was fitted.

In fact, von Bertalanffy growth provided a good description of annual growth of male squat lobster, as judged from the variance explained by the model as a measure of goodness of fit (Chen et al. 1992). For females however, a certain departure from von Berta. lanfy growth was apparent, which caused a nonrandom pattern in the residuals of the fitted model. However, it must be emphasized that the variance explained by the von Bertalanffy model for females was, nevertheless, fairly high. Note also that male growth showed no deviance from the model and only showed a marginally better fit as compared to female growth $\left(\mathrm{r}_{\mathrm{m}}^{2}-\mathrm{r}_{\mathrm{f}}{ }^{2}=0.032\right)$. Thus for both male and female squat lobster, the fitted von Bertalanffy model provided a good first description of annual growth.

Our parameterization of the von Bertalanffy growth function is consistent with results for other crustaceans (Campbell 1983, Anderson 1991, Plaut \& Fishelson 1991, Bergström 1992). Also, female crustaceans normally attain lower size at age than males of the same species (Campbell 1983, Fogarty \& Idoine 1988, Plaut \& Fishelson 1991, Somers \& Kirkwood 1991\}, as in this study. An exception is the work of Bergström (1992) on Pandalus borealis which is a protandric hermaphrodite.

\section{Methodological aspects of maturity function}

Observations of maturity data distribute binomially. Welch \& Foucher (1988) seem to be the first to have highlighted this important feature of maturity data and its consequences in statistical estimation. Further work has acknowledged this advance (Richards et al. 1990, Schnute \& Richards 1990, Trippel \& Harvey 1991). However, some authors are still using procedures which do not take this fact into account (for example, Dugan et al. 1991, Armstrong et al. 1992, Bullock et al. 1992). In this paper, İ used logistic regression (Shabunoghe \& Gore 1987, Hosmer \& Lemeshow 1989), a likelihood-principle based procedure that incorporates the binomial nature of maturity data.

For the particular case of the squat lobster, it is shown that the $5 \%$ plausibility region of the estimated logistic curve is very similar to the $95 \%$ confidence interval, a consequence of large sample size (Welch \& Foucher 1988). For smaller sample sizes, and especially when the data near the size range in which maturation occurs is scarce, it is more convenient to use plausibility regions as explained by Welch \& Foucher (1988).

\section{Biological aspects of maturity analysis}

Female squat lobsters reach maturity at intermediate sizes (ages) as a population average. The transition from immature to mature is successive, and occurs in a range of $5 \mathrm{~mm}$ (from 25 to $30 \mathrm{~mm}$ carapace length). This type of distribution in maturity at size data corresponds to a type II distribution of Trippel \& Harvey (1991), and generally represents populations in a stable condition, i.e. populations in which the proportion of mature individuals reflects those which would occur from a time series of a single year class, where a gain in percent maturity occurs with each passing year (Trippel \& Harvey 1991). Therefore, stability refers to age structure. Based solely on the maturity distribution, in 1991 the female (and by extension, male) Achira population of squat lobster had a stable age structure. The population was also growing and reinvading former habitats after a fishery closure of $3 \mathrm{yr}$ (1989 to 1991) and a previous period of overexploitation (1975 to 1988) which severely contracted latitudinal distribution (Roa \& Bahamonde in press). The facts 
of population growth and expansion (Roa \& Bahamonde in press) and the implications from the maturity distribution suggest a highly beneficial effect of the fishery closure on population recovery.

Nevertheless, the transition from immature to mature occurs within a narrow size range, suggesting that a small change in the size at which females enter the fishery could have a large impact on the removal of reproductive potential, and hence on population renewal. At present, the size at which females enter the fishery (near $33 \mathrm{~mm}$; author's unpubl. results) is above the estimated average at which maturation occurs (between about 25 and $30 \mathrm{~mm}$ ). The size at which males enter the fishery is even greater (near $36 \mathrm{~mm}$; author's unpubl. results). However, to estimate the effect of fishing removal of reproductive potential on population renewal it is not sufficient to know the distance between average size of maturation and the size of recruitment to the fishery. Also needed is a knowledge of mortality rates of the exploited fraction. Future research will help solve this problem.

Acknowledgements. 1 thank the members of the Scientific Advisory Committee on Crustacean Fisheries of the Subsecretariat of Fishing, Republic of Chile, for providing the impetus to do this work and for discussing some preliminary results. Three anonymous referees made many important suggestions and criticisms that greatly improved this work Ignacio Payá helped in performing some statistical analyses and Renato Quiñones read a previous version making useful comments that improved the paper. This work was financed by Convenio Ad-Referendum 10/92 'Análisis Metodológico Pesquería Langostino Colorado' of the Subsecretariat of Fishing to the Fisheries Development Institute of Chile.

\section{LITERATURE CITED}

Anderson, P. J. (1991). Age, growth, and mortality of the northern shrimp Pandalus borealis Kröyer in Pavlov Bay, Alask.a. Fish. Bull. U.S. 89: 541-553

Armstrong, M. P., Musik, J. A., Colvocoresses, J. A. (1992). Age, growth, and reproduction of the goosefish Lophius americanus (Pisces: Lophiiformes). Fish. Bull. U.S. 90: $217-230$

Bergström, B. (1992). Growth, growth modelling and age determination of Pandalus borealis. Mar. Ecol. Prog. Ser. 83: $167-183$

Bhattacharya, C. G. (1967). A simple method of resolution of a distribution into Gaussian components. Biometrics 23 $115-135$

Bullock, L. H., Murphy, M. D., Godcharles, M. F., Mitchell, M. E. (1992). Age, growth, and reproduction of jewfish Epinephelus itajara in the eastern Gulf of Mexico. Fish. Bull. U.S. 90: 243-249

Campbell, A. (1983). Growth of tagged American lobster Homarus americanus, in the Bay of Fundy. Can. J. Fish. Aquat. Sci, 40: 1667-1675

Campbell, A., Robinson, D. G. (1983). Reproductive potential of three American lobster (Homarus americanus) stocks in the Canadian Maritimes. Can. J. Fish. Aquat. Sci. 40 $1958-1967$

Cassie, R. M. (1954). Some uses of probability paper in the analysis of size frequency distributions. Aust. J mar. Freshwat. Res. 5: 513-522

Chen, Y., Jackson, D. A., Harvey, H. H. (1992). A comparison of von Bertalanffy and polynomial functions in modelling fish growth data. Can. J. Fish. Aquat. Sci. 49: 1228-1235

Dugan, J. E., Wenner, A. M., Hubbard, D. M. (1991) Geographic variation in the reproductive biology of the sand crab Emerita analoga (Stimpson) on the California coast. J. exp. mar. Biol. Ecol, 150: 63-81

Fogarty, M. J., Idoine, J. S. (1988). Application of a yield and egg production model based on size to an offshore American lobster population. Trans. Am. Fish. Soc. 117: $350-362$

Fournier, D. A., Sibert, J. R., Majkowski, J., Hampton, J. (1990). MULTIFAN: a likelihood-based method for estimating growth parameters and age composition from multiple length frequency data sets illustrated using data for southern bluefin tuna (Thunnus maccoyii). Can. J. Fish. Aquat. Sci. 47: 301-317

Fournier, D. A., Sibert, J. R., Terceiro, M. (1991). Analysis of length frequency samples with relative abundance data for the Gulf of Maine northern shrimp (Pandalus borealis) by the MULTIFAN method. Can. J. Fish. Aquat. Sci. 48 $591-598$

Grant, A. (1989). The use of graphical methods to estimate demographic parameters. J. mar. biol. Ass. U.K. 69: 367-371

Harding, J. P. (1949). The use of probability paper for the graphical analysis of polymodal frequency distributions. J. mar. biol. Ass. U.K. 28: 141-153

Henmi, Y. (1992). Annual fluctuation of life-history traits in the mud crab Macrophthalmus japonicus. Mar Biol. 113: $569-577$

Hosmer, D. W., Lemeshow, S. (1989). Applied logistic regression. John Wiley and Sons, New York

Macdonald, P. D. M., Green, P. E. J. (1988). User's guide to program MIX: an interactive program for fitting mixtures of distributions. Ichtus Data Systems, Hamilton, ON

Macdonald, P. D. M., Pitcher, T J. (1979). Age-groups from size-frequency data: a versatile and efficient method of analysing distribution mixtures. J. Fish. Res. Bd Can. 36: $987-1001$

Palma, S., Arana, P. (1990). Aspectos reproductivos del langostino colorado (Pleuroncodes monodon) en la zona centro-sur de Chile. Estudios y Documentos Univ. Catolica 1/90 (Mimeo), Valparaiso

Plaut, I., Fishelson, L. (1991). Population structure and growth in captivity of the spiny lobster Panulirus penicillatus from Dahab, Gulf of Aqaba, Red Sea. Mar. Biol. 111: 467-472

Restrepo, V. R., Watson, R. A. (1991). An approach to modeling crustacean egg-bearing fractions as a function of size and season. Can. J. Fish. Aquat. Sci. 48: 1431-1436

Richards, L. J., Schnute, J. T., Hand, C. M. (1990). A multivariate model with a comparative analysis of three lingcod (Ophiodon elongatus) stocks. Can. J. Fish. Aquat. Sci. 47: 948-959

Roa, R., Bahamonde, R. (in press). Growth and espansion of an exploited population of the squat lobster (Pleuroncodes monodon) after 3 years without harvesting. Fish. Res.

Rosenberg, A. A., Beddington, J. R. (1987). Monte-Carlo testing of two methods for estimating growth from lengthfrequency data with general conditions for their applicability. In: Pauly, D., Morgan, G. R. (eds.) Length-based methods in fisheries research. ICLARM Conf. Proc. 13 $283-298$ 
Saila, S. B., Annala, J. H., McKoy, J. L., Booth, J. D. (1979) Application of yield models to the New Zealand rock lobster fishery. N.Z. J. mar. Freshwat. Res. 13: 1-11

Schnute, J. T.. Richards, L. J. (1990). A unified approach to the analysis of fish growth, maturity, and survivorship data. Can. J. Fish. Aquat. Sci. 47: 24 40

Shanubhogue, A., Gore, P. A. (1987). Using logistic regression in ecology. Curr. Sci. 56: 933-936

Somers, I. F., Kirkwood, G. P. (1991). Population ecology of the grooved tiger prawn, Penaeus semisulcatus, in the northwestern Gulf of Carpentaria, Australia: growth, movement, age structure and infestation by the bopyrid parasite Epipenaeon ingens. Aust. J. mar. Freshwat. Res. 42: $349-367$

Sparre, P. (1987). A method for the estimation of growth, mortality, and gear selection/recruitment parameters from

This article was submitted to the editor length frequency samples weighted by catch per effort In: Pauly, D., Morgan, G. R. (eds.) Length-based methods in fisheries research. ICLARM Conf. Proc. 13: 75-102

Sparre, P., Ursin, E., Venema, S. C. (1989). Introduction to tropical fish stock assessment. FAO Fish. Tech. Pap $306 / 1$

Trippel, E. A., Harvey, H. H. (1991). Comparison of methods to estimate age and length of fishes at sexual maturity using populations of white sucker (Catostomus commersoni). Can. J. Fish. Aquat. Sci 48: 1446-1459

Welch, D. W. Foucher, R. P. (1988). A maximum likelihood methodology for estimating length-at-maturity with application to Pacific cod (Gadus macrocephalus) population dynamics. Can. J. Fish. Aquat. Sci. 45: 333-343

Wilkinson, L. (1988). SYSTAT: the system for statistics. SYSTAT, Inc., Evanston, IL

Manuscript first received: January 19, 1993

Revised version accepted: April 30, 1993 